\title{
Interactions between rheumatoid arthritis antibodies are associated with the response to anti-tumor necrosis factor therapy
}

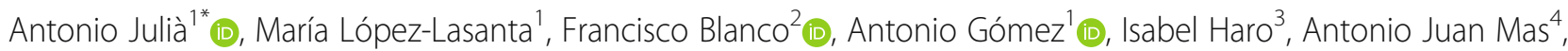

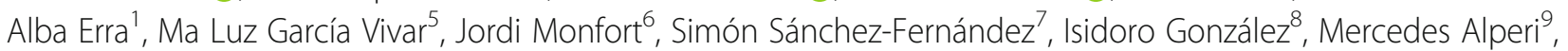
Raúl Castellanos-Moreira ${ }^{10}$, Antonio Fernández-Nebro ${ }^{11}$, César Díaz-Torné ${ }^{12}$, Núria Palau ${ }^{1}$, Raquel Lastra ${ }^{1}$, Jordi Lladós ${ }^{1}$, Raimon Sanmartí ${ }^{10}$ (D) and Sara Marsal ${ }^{1}$ (D)

\begin{abstract}
Background: Blocking of the Tumor Necrosis Factor (TNF) activity is a successful therapeutic approach for 50-60\% of rheumatoid arthritis (RA) patients. However, there are yet no biomarkers to stratify patients for anti-TNF therapy. Rheumatoid factor (RF) and anti-cyclic-citrullinated antibodies (anti-CCP) have been evaluated as biomarkers of response but the results have shown limited consistency. Anti-carbamylated protein (anti-CarP) and anti-peptidylarginine deiminase type 4 (anti-PAD4) antibodies have been much less studied. Despite being linked to common immune processes, the interaction between these markers has not been evaluated yet. Our aim was to analyze the interaction between these four antibodies in relation to the response to anti-TNF therapy.
\end{abstract}

Methods: For this objective, a prospective cohort of $n=80$ RA patients starting anti-TNF therapy was recruited. Serum determinations at baseline were performed for RF, anti-CCP, anti-CarP and anti-PAD4 antibodies using enzyme-linked immunosorbent assays (ELISA). The clinical response to anti-TNF therapy was determined at week 12 using the change in DAS28 score. Association was performed using multivariate linear regression adjusting for baseline DAS28, sex and age.

Results: The interaction between pairs of antibodies was tested by the addition of an interaction term. We found two highly significant antibody interactions associated with treatment response: anti-CarP with anti-PAD4 ( $p=0.0062)$, and anti-CCP with RF ( $p=0.00068)$. The latter antibody interaction was replicated in an independent retrospective cohort of RA patients $(n=199, p=0.04)$.

Conclusions: The results of this study suggest that antibody interaction effects are important factors in the response to anti-TNF therapy in RA.

Keywords: Rheumatoid arthritis, Treatment response, Anti-TNF therapy, Autoantibodies

\footnotetext{
*Correspondence: toni.julia@vhir.org

${ }^{1}$ Rheumatology Research Group, Vall d'Hebron University Hospital Research Institute, 08035 Barcelona, Spain

Full list of author information is available at the end of the article
}

(c) The Author(s). 2021 Open Access This article is licensed under a Creative Commons Attribution 4.0 International License, which permits use, sharing, adaptation, distribution and reproduction in any medium or format, as long as you give appropriate credit to the original author(s) and the source, provide a link to the Creative Commons licence, and indicate if changes were made. The images or other third party material in this article are included in the article's Creative Commons licence, unless indicated otherwise in a credit line to the material. If material is not included in the article's Creative Commons licence and your intended use is not permitted by statutory regulation or exceeds the permitted use, you will need to obtain permission directly from the copyright holder. To view a copy of this licence, visit http://creativecommons.org/licenses/by/4.0/. The Creative Commons Public Domain Dedication waiver (http://creativecommons.org/publicdomain/zero/1.0/) applies to the data made available in this article, unless otherwise stated in a credit line to the data. 


\section{Background}

Rheumatoid arthritis (RA) is the most common chronic inflammatory arthritis, with a Worldwide prevalence of $0.5-1 \%$. Tumor necrosis factor (TNF) is a proinflammatory cytokine that is central to the inflammatory process of RA. Systemic blocking of this cytokine has proven to be a highly efficacious approach to control the disease activity [1]. Despite this major therapeutic advance, up to $40 \%$ of RA patients treated with a TNF blocking agent don't show a significant clinical improvement. Very little knowledge exists on the factors that determine this unfavorable response, and biomarkers have yet to be identified.

RA is characterized by the expression of antibodies against self-antigens, and consequently they have been among the first biomarkers to be evaluated for association with treatment response. Antibodies against the Fc portion of immunoglobulin G -rheumatoid factor (RF)and against cyclic citrullinated peptides (anti-CCP) are currently the two most relevant diagnostic tests for RA [2]. Both autoantibodies have been clearly associated to unfavorable prognosis [3]. However, their association to the response to anti-TNF therapy is much less clear. Previous studies have shown inconclusive or conflicting results [4-6]. Consequently, interest has shifted in analyzing more recently discovered antibodies as potential biomarkers for treatment response.

Anti-peptidylarginine deiminase type 4 (anti-PAD4) antibodies [7] and anti-carbamylated protein (anti-CarP) antibodies [8] are recent markers in RA. Anti-PAD4 antibodies, although not specific for RA, have been associated to a more severe disease phenotype [9]. There is yet scarce data on the association of anti-PAD4 in antiTNF response. A first small study on 40 patients found that patients positive for this antibody had a worse response to therapy [10]. A more recent study involving triple DMARD and anti-TNF therapy treated patients, suggested that anti-PAD4 positive patients had instead a more favorable response [11]. However, the association was not tested individually for each drug arm, so the specific association to TNF blocking is unclear. AntiCarP antibodies occur in up to $40 \%$ of RA patients and, like anti-CCPs, they can appear several years before the onset of the disease. To date, anti-CarP antibodies have not been tested for association with the response to anti-TNF therapy in RA.

The presence of previous conflicting results could be an indication that a more complex relationship exists between antibodies and the response to anti-TNF therapy in RA. From a biological perspective, anti-CarP, antiPAD4, RF and anti-CCP target proteins involved in closely related biological processes. The simultaneous expression of two or more of these antibodies could therefore represent a higher load of specific pathogenic mechanisms. Recent experimental evidence supports the presence of this type of pathogenic interactions between RA autoantibodies [12]. From a clinical perspective, the presence of synergic effects between antibodies could translate into stronger responses to therapy. In the present study we have addressed this question and analyzed, for the first time, the association of antibody interactions with the response to anti-TNF therapy.

\section{Methods}

\section{Patients and samples}

A prospective cohort of $n=80$ RA patients was recruited from 11 university hospitals from Spain. Enrolled patients fulfilled the ACR/EULAR 2010 classification criteria for RA [2] and were starting an anti-TNF therapy. All patients had an active disease at baseline, described as a 28 -joint Disease Activity Score $(\mathrm{DAS} 28) \geq 3.2$. The same day of treatment initiation, blood samples were obtained and the plasma fraction separated and stored at $-80{ }^{\circ} \mathrm{C}$ until analysis.

The validation dataset consisted on a retrospective cohort of $n=199 \mathrm{RA}$ patients that were recruited by the IMID Consortium, a network of rheumatology departments from $n=15$ university hospitals in Spain [13]. All patients fulfilled the ACR/EULAR 2010 classification criteria for RA, and the primary response to anti-TNF therapy at week 12 was collected. Plasma samples were processed following the same procedure.

\section{Antibody measurements}

The four antibodies were analyzed using enzyme-linked immunosorbent assays (ELISA). RF and anti-CCP were measured using the IBL International and the Euro Diagnostica anti-CCP2 ELISA kits, respectively. Positivity for anti-CCP and RF were defined according to the manufacturer's protocols $(\geq 18 \mathrm{U} / \mathrm{ml}$ and $\geq 25 \mathrm{U} / \mathrm{ml}$ for RF and anti-CCP, respectively). Anti-PAD4 titers were measured using the PAD4 autoantibody ELISA kit (Cayman Chemical). Anti-carbamylated proteins IgG autoantibodies (anti-CarP) were determined using a homemade ELISA test using as antigen carbamylated fetal calf serum (FCS). A non-carbamylated version of the FCS was used to control for homocitrulline specificity. Reactivity to non-modified FCS was subtracted from the reactivity to carbamylated FCS and a standard curve of serial dilutions of a pool of four positive samples was used to convert optical density values to arbitrary units (AU). Compared to IgM-RF and anti-CCP2, there is no established threshold for positivity for anti-PAD4 or anti-CarP biomarkers, and antibody titers were directly used to test for association with anti-TNF response.

In the validation cohort, anti-CCP was measured using an electrochemiluminescence assay (Cobas, Roche) and the RF was determined using an immunoturbidimetric 
method (Cobas, Roche). Positivity thresholds were defined using the manufacturer's protocol $(\geq 17 \mathrm{U} / \mathrm{ml}$ and $\geq 14 \mathrm{U} / \mathrm{ml}$ for anti-CCP and RF, respectively).

\section{Statistical analysis}

The primary outcome measure was the change in the DAS28 score $(\triangle \mathrm{DAS} 28)$ between baseline and 12 weeks of anti-TNF therapy [14]. The association between anti-CarP, PAD4, RF and anti-CCP antibodies and treatment response was determined using multivariate linear regression. The multivariate model included sex, age and the baseline DAS28 measure, as described previously [4].

Interaction testing was performed by including an additional interaction term in the multivariate regression model. All pairwise interaction models between the four biomarkers were tested $(n=6)$. Multiple testing significance correction was performed using Bonferroni's adjustment.

\section{Results}

\section{Patient characteristics}

Baseline characteristics of the prospective patient cohort are summarized in Table 1 . Clinical measures are comparable to previous RA cohorts. The four autoantibody titers were determined in $100 \%$ of the patients. $65 \%$ of the RA patients were positive for RF and $72 \%$ of for anti-CCP. An average reduction of $1.96(+/-1.33)$ points in the DAS28 score was observed for the global cohort, which is consistent with previous studies [15].

\section{Association of antibodies with anti-TNF response}

Multivariate linear regression was used to simultaneously test for association between anti-CCP, RF, anti-CarP and anti-PAD4 antibodies and treatment response. At the single-marker level, none of the autoantibodies were found to be significantly associated with an improvement in the DAS28 (Supplementary Table S1). We next tested for the presence of interaction effects between all six pairwise antibody combinations in relation to treatment response. We found a highly significant antibody interaction between anti-CarP and anti-PAD4 $(P=0.0062)$, and between anti-CCP and RF $(P=0.00068)$ with anti-TNF response (Table 2). anti-CarP:anti-PAD4 interaction was associated with a worse response to therapy (interaction coefficient $\beta<0$ ) and anti-CCP:RF interaction with a better response to TNF blocking $(\beta>0)$. The remaining four pairwise antibody interactions were not significant $(P>$ 0.05). After adjusting for multiple testing, anti-CarP:antiPAD4 and anti-CCP:RF interactions remained statistically significant $(P=0.0041$ and $P=0.037$, respectively).

Using an independent cohort of 199 RA patients, we replicated the interaction between anti-CCP and RF $(P=0.044$, Fig. 1). Like in the prospective cohort, the interaction was also found to be positive, indicating that the simultaneous presence of both antibodies is associated with a better response to anti-TNF therapy.

Table 1 Baseline characteristics of the prospective RA patient cohort

\begin{tabular}{|c|c|c|c|}
\hline Baseline variable & $\begin{array}{l}\text { Total } \\
(n=80)\end{array}$ & Responders $(n=67)$ & Non-Responders $(n=13)$ \\
\hline Age, years (mean $\pm S D$ ) & $54.2 \pm 11.93$ & $53.12 \pm 11.65$ & $59.7 \pm 12.32$ \\
\hline Gender (Female,n \%) & $66(82.5)$ & $54(80.6)$ & $12(92)$ \\
\hline Previous csDMARDs (mean \pm SD) & $1.85 \pm 1.28$ & $1.82 \pm 1.24$ & $2 \pm 1.53$ \\
\hline Disease duration, years (median/IQR) & $9.74(9.25)$ & $9.24(9.5)$ & $12.31(11.41)$ \\
\hline ESR, mm/h (median/IQR) & $35.1(28.75)$ & $36.52(34)$ & $27.7(21.17)$ \\
\hline CRP, mg/dL (median/lQR) & $1.63(1.27)$ & $1.63(1.23)$ & $1.62(1.47)$ \\
\hline MTX dosage (mean mg/week) & 18.46 & 18.25 & 19.64 \\
\hline Prednisone use (n, \%) & $60(75)$ & $50(74.6)$ & $10(77)$ \\
\hline \multicolumn{4}{|l|}{ Smoking (n, \%) } \\
\hline Never & $54(67.5)$ & $44(65.7)$ & $10(77)$ \\
\hline Past & $10(12.5)$ & $6(9)$ & $3(23)$ \\
\hline Current & $16(20)$ & $17(25.3)$ & $0(0)$ \\
\hline Adalimumab & $16(20)$ & $15(22.4)$ & $1(8)$ \\
\hline Certolizumab & $24(30)$ & $21(31.3)$ & $3(23)$ \\
\hline Etanercept & $19(23.75)$ & $16(23.4)$ & $3(23)$ \\
\hline Golimumab & $21(26.25)$ & $15(22.4)$ & $6(46)$ \\
\hline
\end{tabular}

Clinical and epidemiological characteristics of the prospective cohort. Patients are shown globally and split according to the EULAR response at week 12 (Good and Moderate responders aggregated into a unique Responder group). MTX methotrexate; CSDMARDs conventional synthetic DMARDs; IQR interquartile range; SD standard deviation 
Table 2 Association results for RA antibody interactions with anti-TNF response

\begin{tabular}{|c|c|c|c|}
\hline \multirow[b]{2}{*}{ Antibody pair } & \multicolumn{3}{|c|}{$\begin{array}{l}\text { Regression coefficient }(95 \% \mathrm{Cl}), \\
P \text {-value }\end{array}$} \\
\hline & Interaction effect & Antibody \#1 main effect & Antibody \#2 main effect \\
\hline $\begin{array}{l}\text { \#1: Anti-CCP } \\
\text { \#2: RF }\end{array}$ & $\begin{array}{l}2.74(1.20,4.26) \\
P=0.00068\end{array}$ & $\begin{array}{l}-1.21(-2.14,-0.28) \\
P=0.012\end{array}$ & $\begin{array}{l}-2.24(-3.57,-0.91) \\
P=0.0013\end{array}$ \\
\hline $\begin{array}{l}\text { \#1: RF } \\
\text { \#2: Anti-PAD4 }\end{array}$ & $\begin{array}{l}-2.7 \mathrm{e}-4(-7.5 \mathrm{e}-4,1.9 \mathrm{e}-4) \\
P=0.25\end{array}$ & $\begin{array}{l}0.17(-0.89,1.21) \\
P=0.75\end{array}$ & $\begin{array}{l}1.9 \mathrm{e}-4(-2.1 \mathrm{e}-4,5.9 \mathrm{e}-4) \\
P=0.34\end{array}$ \\
\hline $\begin{array}{l}\text { \#1: Anti-PAD4 } \\
\text { \#2: Anti-CarP }\end{array}$ & $\begin{array}{l}-1.3 \mathrm{e}-6(-2.20-6,3.8 \mathrm{e}-6) \\
P=0.0062\end{array}$ & $\begin{array}{l}2.2 \mathrm{e}-4(-3.6 \mathrm{e}-5,4.8 \mathrm{e}-4) \\
P=0.090\end{array}$ & $\begin{array}{l}1.3 e-3(9.6 e-5,2.5 e-3) \\
P=0.035\end{array}$ \\
\hline $\begin{array}{l}\text { \#1: Anti-CCP } \\
\text { \#2: Anti-PAD4 }\end{array}$ & $\begin{array}{l}-2.5 e-4(-7.5 e-4,2.5 e-4) \\
P=0.33\end{array}$ & $\begin{array}{l}0.12(-0.94,1.18) \\
P=0.83\end{array}$ & $\begin{array}{l}1.8 \mathrm{e}-4(-2.6 \mathrm{e}-4,6.2 \mathrm{e}-4) \\
P=0.41\end{array}$ \\
\hline $\begin{array}{l}\text { \#1: Anti-CCP } \\
\text { \#2: Anti-CarP }\end{array}$ & $\begin{array}{l}8.9 e-4(-8.9 e-4,2.7 e-3) \\
P=0.32\end{array}$ & $\begin{array}{l}-0.45(-1.38,0.48) \\
P=0.34\end{array}$ & $\begin{array}{l}-8.4 \mathrm{e}-4(-2.5 \mathrm{e}-3,7.9 \mathrm{e}-4) \\
P=0.31\end{array}$ \\
\hline $\begin{array}{l}\text { \#1: RF } \\
\# 2: \text { Anti-CarP }\end{array}$ & $\begin{array}{l}-5.39 \mathrm{e}-4(-3.1 \mathrm{e}-3,1.9 \mathrm{e}-3) \\
P=0.67\end{array}$ & $\begin{array}{l}-0.17(-0.99,0.65) \\
P=0.67\end{array}$ & $\begin{array}{l}3.87 \mathrm{e}-3(-2 \mathrm{e}-3,2.8 \mathrm{e}-3) \\
P=0.75\end{array}$ \\
\hline
\end{tabular}

Each row shows the association results for each of the six possible pairwise interactions between the four RA antibodies and anti-TNF treatment response, adjusting for baseline DAS28, sex and age. Regression coefficients ( $\beta$ value) with $95 \%$ confidence intervals $(C \mathrm{Cl})$ and $P$ values for association are shown for the interaction term (first column) and for the independent effect of each antibody (second and third columns). In bold, interaction $P$-values that are significant after correcting for multiple testing. A highly significant interaction was found for anti-CCP:RF and anti-PAD4:anti-CarP interactions with anti-TNF response. None of the remaining four antibody interactions showed a significant association, even at the nominal $(P<0.05)$ level

\section{Discussion}

The identification of factors associated with the response to anti-TNF therapy is a major objective for treatment personalization in RA. Diagnostic autoantibodies, like rheumatoid factor and anti-CCP, are appealing for this task since they are already integrated into the standard clinical routine. However, conflicting results have been reported and their association to treatment response to anti-TNF is yet not clear. We hypothesized that this inconsistency could be due to the presence of interaction effects between the autoantibodies. In the present study we have tested this hypothesis for the first time. Using a prospective cohort of RA patients starting anti-TNF therapy, we have found that the interaction between anti-CCP and RF and the interaction between anti-CarP and anti-PAD4 antibodies are both strongly associated with the clinical response at week 12 . The present results suggest that interactions between antibodies are

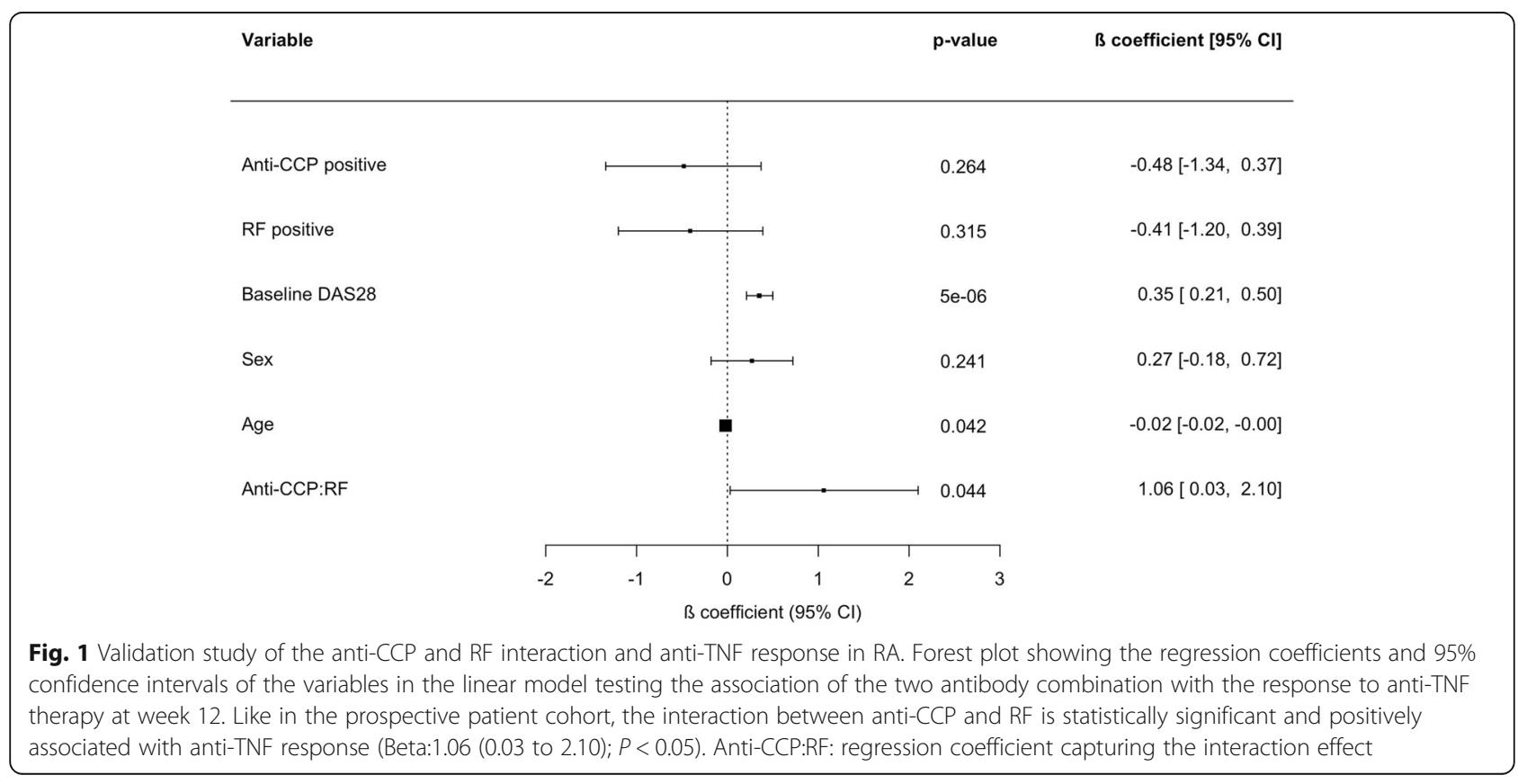


important in the response to anti-TNF therapy, and provide an explanation for the previous conflicting evidence.

Our study shows that the presence of both anti-CCP and RF antibodies is needed for a favorable response to anti-TNF therapy. Several previous studies have analyzed the association of either antibody in relation with the response to anti-TNF drugs. The results, however, have been largely inconsistent or inconclusive [16]. In those few studies where both antibodies were determined, the presence of interactions was not evaluated. Here we show that, when the interaction is considered, a strong and positive association between these two classic antibodies and the clinical response emerges. From a statistical perspective, when interaction effects are present and are strong, not taking them into account in the association model can lead to inconsistent findings [17]. Failing to take this into account could therefore explain the lack of reproducibility of previous studies with anti$\mathrm{CCP}$ and RF and treatment response.

The interaction association identified between anti$\mathrm{CCP}$ and RF with the response to anti-TNF therapy is in accordance with recent findings at the functional level. In a recent study, macrophages -the main producers of TNF in the RA joint- have been shown to secrete much higher TNF cytokine levels when stimulated with both anti-CCP and RF antibodies than when stimulated with anti-CCP alone [12]. According to these results, disease activity in RA patients that express both anti-CCP and RF might be partially due to the overexpression of TNF by macrophages reacting strongly to the combination of the two antibodies. Instead, in patients expressing only one of the antibodies or in seronegative patients, this synergic production of TNF by the synovial macrophage will not occur, and other inflammatory pathways will therefore have a more predominant role in disease activity. Our results show that, although still effective in some patients, anti-TNF therapy has a much less pronounced therapeutic effect in patients with only one antibody compared to patients positive for both antiCCP and RF.

In our study we also found that the interaction between anti-CarP and anti-PAD4 is associated to antiTNF response. In this case, we found that the higher the expression of both antibodies, the worse the patients responded to TNF blocking. Compared to anti-CCP and RF, these two antibodies do not physically interact at the molecular level. However, the two antibodies share a strong association to neutrophil activity. PAD4 is responsible for most of the citrullinated epitopes in RA [18] and is specifically expressed in neutrophils. Protein carbamylation is caused by an increase in tissue cyanate due to the activity of neutrophil myeloperoxidase during inflammation in RA. A higher abundance of both antibodies therefore suggests a more predominant role of neutrophils in RA pathology. According to our results, patients with a strong neutrophil-mediated inflammation are less sensitive to therapeutic TNF blocking. This is in line with recent experimental evidence showing that neutrophil activation and TNF have independent effects in RA pathology [19]. New therapies that directly affect neutrophil activation like, granulocytemacrophage colony-stimulating factor blocking, are currently under way in RA [20]. Our results suggest that the simultaneous analysis of anti-PAD4 and anti-CarP antibodies could be a useful biomarker of response in this new therapeutic approach.

The present study has limitations. Despite most previous studies analyzing the association of antibodies to anti-TNF response have used similar or smaller sample sizes, the number of patients used in our prospective study is relatively modest. Having a larger patient cohort would have enabled a more precise estimation of the interaction effects, with narrower confidence intervals. To this regard, while the quantitative nature of the $\triangle \mathrm{DAS} 28$ can help increase the power to identify biomarkers of drug efficacy, small improvements in DAS28 might not have a translation into clinically meaningful responses. More patient data on the four antibodies will help to better define this boundary. Finally, the comparison of the interaction association between different types of antiTNF drugs could not be explored. There is evidence that TNF blocking agents work through biological mechanisms that are not entirely overlapping $[21,22]$. An individual analysis of each drug type might reveal stronger interactions and better biomarker utility. For this aspect to be adequately tested, larger drugspecific prospective patient cohorts will need to be analyzed.

\section{Conclusion}

In summary, in the present study we have found that RA antibodies show significant interaction effects with the response to anti-TNF therapy. The observed interactions are in line with pathogenic mechanisms recently described in RA. Our findings also provide an explanation for the lack of consistency observed in previous studies, in which antibodies were analyzed independently. These results leverage the potential of antibodies as biomarkers for anti-TNF response in RA.

\section{Abbreviations}

TNF: Tumor Necrosis Factor; RA: Rheumatoid Arthritis; DAS28: Disease Activity Score for 28 joints; RF: Rheumatoid factor; anti-CCP: Anti-cyclic-citrullinated antibodies; anti-CarP: Anti-carbamylated protein antibodies; anti-PAD4: Antipeptidylarginine deiminase type 4 antibodies; ELISA: Enzyme-linked immunosorbent assay; ACR: American College of Rheumatology; EULAR: European League Against Rheumatism 


\section{Supplementary Information}

The online version contains supplementary material available at https://doi. org/10.1186/s12891-021-04248-y.

Additional file 1: Supplementary Table S1. Association results for the four antibodies and anti-TNF response at week 12 in the prospective cohort (independent effects).

\section{Acknowledgements}

Not Applicable.

\section{Authors' contributions}

All authors were involved in drafting the article and all authors approved the final version to be published. Study conception and design. AJ, RS, SM. Acquisition of data. MLL, FB, IH, AJM, AE, MLGV, JM, SSF, IG, MA, RCM, AFN, CDT, $R S$, NP, RL, SM. Analysis and interpretation of data. AJ, MLL, AG, JLL, RS, SM.

\section{Funding}

This project was supported by UCB Pharma. The funders had no role in the study design, data analysis, data interpretation or writing the manuscript.

\section{Availability of data and materials}

The datasets used and/or analysed during the current study available from the corresponding author on reasonable request.

\section{Declarations}

\section{Ethics approval and consent to participate}

The Vall d'Hebron University Hospital (Barcelona, Spain) ethics committee approved the study with approval number SMB-CZP-2014-03. The study was conducted in accordance with the Declaration of Helsinki. All participants gave their written informed consent to participate.

\section{Consent for publication}

Not applicable.

\section{Competing interests}

None to declare.

\section{Author details}

'Rheumatology Research Group, Vall d'Hebron University Hospital Research Institute, 08035 Barcelona, Spain. ${ }^{2}$ Rheumatology Department, INIBIC-Hospital Universitario A Coruña, A Coruña, Spain. ${ }^{3}$ Unitat de Síntesi i Aplicacions Biomèdiques de Pèptids, IQAC-CSIC, Barcelona, Spain. ${ }^{4}$ Rheumatology Department, Hospital Universitario Son Llàtzer, Mallorca, Spain. ${ }^{5}$ Rheumatology Department, Hospital Universitario Basurto, Bilbao, Spain. ${ }^{6}$ Rheumatology Department, Hospital del Mar, Barcelona, Spain. ${ }^{7}$ Rheumatology Department, Hospital General La Mancha Centro, Ciudad Real, Spain. ${ }^{8}$ Rheumatology Department, Hospital Universitario La Princesa, Madrid, Spain. ${ }^{9}$ Rheumatology Department, Hospital Universitario Central de Asturias, Oviedo, Spain. ${ }^{10}$ Rheumatology Department, Fundació Clínic Recerca Biomèdica, Barcelona, Spain. " Rheumatology Department, Hospital Regional Universitario de Málaga, Málaga, Spain. ${ }^{12}$ Rheumatology Department, Hospital de la Santa Creu i Sant Pau, Barcelona, Spain.

Received: 1 February 2021 Accepted: 12 April 2021

Published online: 21 April 2021

\section{References}

1. McInnes IB, Schett $G$. The pathogenesis of rheumatoid arthritis. N Engl J Med. 2011:365(23):2205-19. https://doi.org/10.1056/NEJMra1004965.

2. Kay J, Upchurch KS (2012) ACR/EULAR 2010 rheumatoid arthritis classification criteria. Rheumatol 51 Suppl 6:vi5-9. doi:https://doi.org/10.1 093/rheumatology/kes279.

3. Smolen JS, Landewé R, Bijlsma J, Burmester G, Chatzidionysiou K, Dougados $M$, et al. EULAR recommendations for the management of rheumatoid arthritis with synthetic and biological disease-modifying antirheumatic drugs: 2016 update. Ann Rheum Dis. 2017;76(6):960-77. https://doi.org/1 0.1136/annrheumdis-2016-210715.
4. Potter C, Hyrich K, Tracey A, Lunt M, Plant D, Symmons D, et al. Association of rheumatoid factor and anti-cyclic citrullinated peptide positivity, but not carriage of shared epitope or PTPN22 susceptibility variants, with anti-tumour necrosis factor response in rheumatoid arthritis. Ann Rheum Dis. 2009;68(1):69-74. https://doi.org/10.1136/ard.2 007.084715.

5. Klaasen R, Cantaert T, Wijbrandts CA, Teitsma C, Gerlag DM, Out TA, et al. The value of rheumatoid factor and anti-citrullinated protein antibodies as predictors of response to infliximab in rheumatoid arthritis: an exploratory study. Rheumatol. 2011;50(8):1487-93. https://doi.org/10.1093/rheuma tology/ker010.

6. Martin-Mola E, Balsa A, García-Vicuna R, Gómez-Reino J, González-Gay MA, Sanmartí $R$, et al. Anti-citrullinated peptide antibodies and their value for predicting responses to biologic agents: a review. Rheumatol Int. 2016;36(8): 1043-63. https://doi.org/10.1007/s00296-016-3506-3.

7. Harris ML, Darrah E, Lam GK, Bartlett SJ, Giles JT, Grant AV, et al. Association of autoimmunity to peptidyl arginine deiminase type 4 with genotype and disease severity in rheumatoid arthritis. Arthritis Rheum. 2008;58(7):1958-67. https://doi.org/10.1002/art.23596.

8. Shi J, van de Stadt LA, Levarht EN, Huizinga TW, Toes RE, Trouw LA, et al. Brief report: anti-carbamylated protein antibodies are present in arthralgia patients and predict the development of rheumatoid arthritis. Arthritis Rheum. 2013;65(4):911-5. https://doi.org/10.1002/art.37830.

9. Halvorsen EH, Pollmann S, Gilboe I-M, van der Heijde D, Landewé R, Ødegård S, et al. Serum IgG antibodies to peptidylarginine deiminase 4 in rheumatoid arthritis and associations with disease severity. Ann Rheum Dis. 2008;67(3):414-7. https://doi.org/10.1136/ard.2007.080267.

10. Halvorsen E, Haavardsholm E, Pollmann S, Boonen A, van der Heijde D, Kvien T, et al. Serum IgG antibodies to peptidylarginine deiminase 4 predict radiographic progression in patients with rheumatoid arthritis treated with tumour necrosis factor-a blocking agents. Ann Rheum Dis. 2009;68(2):24952. https://doi.org/10.1136/ard.2008.094490.

11. Darrah E, Yu F, Cappelli LC, Rosen A, O'Dell JR, Mikuls TR. Association of baseline peptidylarginine deiminase 4 autoantibodies with favorable response to treatment escalation in rheumatoid arthritis. Arthritis Rheum. 2019;71(5):696-702. https://doi.org/10.1002/art.40791.

12. Laurent L, Anquetil F, Clavel C, Ndongo-Thiam N, Offer G, Miossec P, et al. IgM rheumatoid factor amplifies the inflammatory response of macrophages induced by the rheumatoid arthritis-specific immune complexes containing anticitrullinated protein antibodies. Ann Rheum Dis. 2015;74(7):1425-31. https://doi.org/10.1136/annrheumdis-2013-204543.

13. Julia A, Gonzalez I, Fernandez-Nebro A, Blanco F, Rodriguez L, Gonzalez A, et al. A genome-wide association study identifies $S L C 8 A 3$ as a susceptibility locus for ACPA-positive rheumatoid arthritis. Rheumatol. 2016;55(6):1106-11. https://doi.org/10.1093/rheumatology/kew035.

14. Fransen J, Van Riel P. The disease activity score and the EULAR response criteria. Clin Exp Rheumatol. 2005;23(5 Suppl 39):S93-9.

15. Hyrich KL, Watson KD, Silman AJ, Symmons DP. Predictors of response to anti-TNF-alpha therapy among patients with rheumatoid arthritis: results from the British Society for Rheumatology biologics register. Rheumatol. 2006;45(12):1558-65. https://doi.org/10.1093/rheumatology/ kel149.

16. de Brito RS, Baldo DC, Andrade LEC. Clinical and pathophysiologic relevance of autoantibodies in rheumatoid arthritis. Adv Rheum. 2019;59(1):2.

17. Jaccard J, Turrisi R. Interaction effects in multiple regression, vol. 72: Sage; 2003. https://doi.org/10.4135/9781412984522.

18. Blachère NE, Parveen S, Frank MO, Dill BD, Molina H, Orange DE. High-titer rheumatoid arthritis antibodies preferentially bind fibrinogen Citrullinated by Peptidylarginine Deiminase 4. Arthritis Rheum. 2017;69(5):986-95. https:// doi.org/10.1002/art.40035.

19. Cook AD, Lee M-C, Saleh R, Khiew H-W, Christensen AD, Achuthan A, et al. TNF and granulocyte macrophage-colony stimulating factor interdependence mediates inflammation via CCL17. JCl insight. 2018;3(6). https://doi.org/10.1172/jci.insight.99249.

20. Burmester GR, Mclnnes IB, Kremer J, Miranda P, Korkosz M, Vencovsky J, et al. A randomised phase Ilb study of mavrilimumab, a novel GM-CSF receptor alpha monoclonal antibody, in the treatment of rheumatoid arthritis. Ann Rheum Dis. 2017;76(6):1020-30. https://doi.org/10.1136/a nnrheumdis-2016-210624.

21. Nestorov I (2005) Clinical pharmacokinetics of tumor necrosis factor antagonists. J Rheumatol (Suppl 74):13-18. 
22. Nesbitt A, Fossati G, Bergin M, Stephens P, Stephens S, Foulkes R, et al. Mechanism of action of certolizumab pegol (CDP870): in vitro comparison with other anti-tumor necrosis factor a agents. Inflamm Bowel Dis. 2007; 13(11):1323-32. https://doi.org/10.1002/ibd.20225.

\section{Publisher's Note}

Springer Nature remains neutral with regard to jurisdictional claims in published maps and institutional affiliations.

Ready to submit your research? Choose BMC and benefit from:

- fast, convenient online submission

- thorough peer review by experienced researchers in your field

- rapid publication on acceptance

- support for research data, including large and complex data types

- gold Open Access which fosters wider collaboration and increased citations

- maximum visibility for your research: over $100 \mathrm{M}$ website views per year

At $B M C$, research is always in progress.

Learn more biomedcentral.com/submissions 